ISSN: 2146-3042

DOI:

\title{
İç Denetim Süreçlerini İyileştirme ve Risk Yönetimi Araçları: Yalın Altı Sigma ve FMEA *
}

\author{
Seval Kardeş SELIMOĞLU** \\ Gül YEŞİLÇELEBİ*** \\ Mehtap ALTUNEL ${ }^{* * * *}$
}

\begin{abstract}
ÖZET
İsletmelerin yapısında var olan karmaşıklık, 2019 yılı itibariyle dünyayı etkisi altına alan COVID-19 salgını ile daha da karmaşık hale gelmiştir. İşletmelerin iş yapışşsekillerini değiştirmesi ve salgından korunmak adına alınan önlemler kapsamında, faaliyetlerin uzaktan yürütülmesi birçok riski de beraberinde getirmiştir. Her geçen gün artan risklerle birlikte, iç denetimin etkin şekilde yürütülmesinin önemi artmış ve yeni yaklaşımların kullanılması zorunlu hale gelmiştir. Bu çalışmada, iç denetimde süreçlerin iyileştirilmesi ve risklerin belirlenmesi aşamalarında kullanılmak üzere, risk yönetim aracı olarak Yalın Altı Sigma kapsamında sunulan Tanımla-Ölçme-Analiz Etme-İyileştirme-Kontrol (Define-MeasureAnalyze-Improvement-Control/DMAIC ) modeli ve bu model içerisine gömülü olan Hata Türü ve Etkileri Analizi (Failure Mode and Effects Analysis-FMEA) aracı olmak üzere iki yaklaşım önerilmiştir. Çalışmada, iç denetimin Yalın Altı SigmaDMAIC modeli ve Hata Türü ve Etkileri Analizi ile olan ilişkisi incelenmiştir. Süreçlerin iyileştirilmesinde kullanılan birçok yaklaşım olmakla birlikte, çalışma kapsamında önerilen bu iki yaklaşım, özellikle işsüreçlerinin verimliliğine, etkililiğine ve tutumluluğuna odaklanan iç denetimin, riskleri değerlendirmesi, süreçteki zayıflıkları belirlemesi ve iyileştirilmesi için tavsiyelerde bulunmaktadir.
\end{abstract}

Anahtar Kelimeler: FMEA, Yalın Altı Sigma, İç Denetim.

JEL Sinıflandırması: M10, M42.

\begin{abstract}
Improvement of Internal Audit Processes and Risk Management Tools: FMEA and Six Sigma

\section{ABSTRACT}

In addition to the complexity inherent in businesses, the COVID-19 pandemic that affected the world as of 2019 has made this even more complex. Changing the way businesses do business and conducting activities remotely within the scope of the measures taken to protect against the epidemic has brought many risks. With the increasing risks day by day, the importance of conducting internal audit has increased and it has become necessary to use new approaches. In this study, two approaches are proposed as a risk management tool, the Lean Six Sigma-DMAIC model and the Failure Mode and Effects Analysis (FMEA) tool embedded in the DMAIC model, to be used in the stages of improving processes and identifying risks in internal auditing. In the study, the relationship between internal audit and FMEA and Six Sigma was examined. Although there are many approaches used in the improvement of processes, these two approaches suggested within the scope of the study, especially focusing on the efficiency, effectiveness and frugality of business processes, make recommendations for internal audit to assess risks, identify weaknesses in the process and improve them.
\end{abstract}

Keywords: FMEA, Lean Six Sigma, Internal Audit

Jel Classification: M10, M42.

* Bu makale, 23-25 Nisan 2021 tarihleri arasında gerçekleștirilen VI. Uluslararası Muhasebe ve Finans Sempozyumunda bildiri olarak sunulmuştur.

Makale Gönderim Tarihi: 10.06.2021, Makale Kabul Tarihi: 22.07.2021, Makale Türü: Kuramsal Makale

${ }^{* *}$ Prof. Dr., Anadolu Üniversitesi, İktisadi ve İdari Bilimler Fakültesi, sselimoglu@anadolu.edu.tr, ORCID: 0000-0003-1185-9980.

*** Dr. Öğr. Üyesi, Gümüşhane Üniversitesi, Uygulamalı Bilimler Yüksekokulu, gyesilcelebi@hotmail.com, ORCID: 0000-0001-8558-4452.

**** Anadolu Üniversitesi, Sosyal Bilimler Enstitüsü, altunelmehtapp@gmail.com, ORCID: 0000-0003-31497753. 


\section{GIRIŞ̧}

Küreselleşmenin iş dünyasında yaşattığı karmaşıklık COVID-19 salgını ile birlikte daha da artmış ve çeşitli etkileri olmuştur. Uzaktan ve esnek çalışma modelleri ile işletmelerin iş yapış şekilleri büyük ölçüde değişmiştir. İşletmelerin, salgından korunmak adına aldığı önlemler kapsamında, faaliyetlerini uzaktan yürütmesi birçok riski de beraberinde getirmiştir. Her geçen gün artan risklerle birlikte, iç denetimin etkin şekilde yürütülmesinin önemi artmış ve yeni yaklaşımların kullanılması zorunlu hale gelmiştir. Bu çalışmada, iç denetimde süreçlerin iyileştirilmesi ve risklerin belirlenmesi aşamalarında kullanılmak üzere Yalın Altı Sigma- Define-Measure-Analyze-Improvement-Control/DMAIC) modeli ve Hata Türü ve Etkileri Analizi (Failure Mode and Effects Analysis-FMEA) araçlarından bahsedilmiştir.

Altı Sigma, işletmelerin sorunlara neden olan temeli belirlemek ve düzeltmek için, daha doğru ve niceliksel bir yaklaşım geliştirmesini sağlayan kontrol edici bir araç seti şeklinde ifade edilmektedir. Bu yaklaşım, iç denetim biriminin daha faydalı denetim tavsiyeleri (Altı Sigma etkisi) yapmasına ve kuruma değer katmayan maliyetlerden kaçınarak "Yalın" etki adı verilen uyumla ilgili maliyetleri azaltmasına yardımcı olmaktadır. Ayrıca, iç denetçilerin operasyonel aşamada tüm sistem ve süreçlerde karşılaşılan riskleri değerlendirmesine katkı sağlamaktadır (Hafez, 2015: 44). Kuşkusuz, her iç denetim uygulamasının diğerlerinden farklı ve kendine özgü özellikleri vardır, bu nedenle Altı Sigma kavramının belirli ilkeleri, iç denetimin tüm süreçlerine sıkı bir şekilde yerleştirilemez ve uygulanamaz. Ancak, faaliyetlerin sürekli izlenmesinde, hata ve eksikliklerin giderilmesinde kullanılan Altı Sigma kavramının temel ilkeleri, iç denetimde kesinlikle en önemli ve uygulanabilir olanıdır. Bu faaliyetler şüphesiz, iç denetimin genel kalitesine katkıda bulunur (Djordjevic vd., 2014: 245). Bu bağlamda, Yalın Altı Sigma kapsamında sunulan TanımlaÖlçme-Analiz Etme-İyileştirme-Kontrol (Define-Measure-Analyze-ImprovementControl/DMAIC) modeli, iç denetim standartlarıyla uyumlu, disiplinli, risk temelli bir yaklaşım olarak hizmet etmektedir. Denetim ekibine; temel nedenleri daha iyi saptamak, uyumsuzluk alanlarını ölçmek ve belgelemek ve işletme giderlerini azaltmanın yollarını önermek için araçlar sağlamaktadır (Aghili, 2009: 43). DMAIC modeli içerisinde bulunan "Ölçme" kapsamında birçok araç kullanılmaktadır ve bunlardan biri Hata Türü ve Etkileri Analizi (FMEA)'dir. FMEA, geleneksel olarak ürünlerdeki bilinen veya potansiyel sorunları müşteriye ulaşmadan önce belirlemek ve ortadan kaldırmak için kullanılan bir mühendislik tekniği olarak ifade edilmektedir. Dolayısıyla FMEA, bir sürecin tasarımında veya ürünün üretiminde sorunların ortaya çıkma olasılığını (riskleri) değerlendirerek faaliyetlerin başarılı şekilde yürütülmesini sağlamaktadır. Bu risk analizinin kullanım alanı, ürünler üzerindeki potansiyel riskleri belirlemekle sınırlı kalmamıştır. Aynı zamanda bu yaklaşım, iç denetçilerin denetim faaliyetlerini yürütürken iç denetim planının ne kadar etkili olduğu yönünde araştırma yapılabilmesine fursat tanımaktadır (Munro, 2014). Bu noktada, FMEA iç denetim faaliyetleri yürütülürken işletmenin tüm süreçlerinde nelerin ters gittiği veya gidebileceği yönünde araştırmaların yapılmasına yardımcı olmaktadır.

Yalın Altı Sigma ve FMEA'ya ilişkin birçok disiplinden ulusal ve uluslararası çalışma bulunmakla birlikte, denetim disiplini kapsamında alan yazın taraması yapıldığında, 
Türkiye'de bu kavramla bağdaştırılmış çalışmanın yer almadığı tespit edilmiştir ${ }^{1}$. Bu bağlamda, çalışmanın Yalın Altı Sigma, FMEA ve iç denetim kavramlarının birlikte değerlendirmesi ve Yalın Altı Sigma ve FMEA'nın iç denetime sağladığı katkıları ortaya koymak adına alan yazına katkı sağlayacağı düşünülmektedir. Uluslararası alan yazın incelendiğinde ise Aghili (2009) tarafından iç denetim ve Altı Sigma yaklaşımı birlikte ele alınarak Altı Sigma-DMAIC modeli ve iç denetim süreçleri kapsamında açıklamalara ayrıntılı yer verilmiştir. Çalışma sonucunda DMAIC modelinin iç denetim standartlarıyla uyumlu, risk temelli bir yaklaşım olduğuna ulaşılmıştır. Bir diğer çalışma olan Djordjevic vd. (2014) tarafından iç denetim ve Yalın Altı Sigma kavramları ele alınarak faaliyet denetimi, Yalın ve Altı Sigma kavramlarının karşılaştırmalı incelemesi yapılmıştır. Çalışma sonucunda işletmelerin iç denetim ve Yalın Altı Sigma kavramını benimsemeleri sonucu süreçlerinde önemli bir gelişme sağladığı, bunun sonucunda rekabet avantajı elde ettiği ve bunun işletmelerin performansına olumlu yönde katkı sağladığ 1 sonucuna ulaşılmıştır.

Bu çalışma kapsamında, öncelikle iç denetim kavramı kısa bir şekilde ele alınmış, ardından Yalın Altı Sigma ve FMEA ile olan ilişkisi incelenmiş ve son olarak ulaşılan sonuçlara yer verilmiştir.

\section{2. İÇ DENETIM}

Günümüzün küresel iş ortamında, işletmeler, küreselleşme ve sürekli artan rekabetlerden kaynaklanan değişikliklerle karşı karşıyadır. Bu değişiklikler, işletmelerin risklere maruz kalmasını artırmaktadır. Bu riskleri proaktif olarak belirleme, değerlendirme, raporlama ve izleme konusundaki başarısızlık, bir işletmenin itibarına ve gelirlerine önemli zararlar verebilir (Choo ve Goh, 2015: 364). Risk, işletmelerin amaçlarına ulaşmasına etki edecek olayların meydana gelme olasılığ olarak tanımlanmaktadır. Risklerle birlikte riskle mücadele konusunun öneminin artmasının yanında geleneksel risk yönetim anlayışı bu karmaşık yapıda etkili değildir. Dolayısıyla olaylara sistematik bakış açısı geliştiren, daha entegre analizler yapılması olanağı sunan, proaktif bir hareket tarzını benimseyen kurumsal risk yönetimi anlayışı benimsenmiştir. Risklerle mücadele konusunda iç denetime de görev düşmektedir (Bozkurt, 2010: 17).

İç denetim faaliyetleri, işletmenin finansal ve finansal olmayan her türlü faaliyeti ile alakalı sunulan bilgilerin doğruluğu ve güvenilirliğine ilişkin, işletme yönetimine ve bilgi kullanıcılarına makul güvence sağlamaktadır. İç denetim, işletmede mevcut olan risklerin yönetilmesi ve bu risklerin etkilerinin en aza indirilmesi, iç ve diş düzenlemelere karşı uyumun sağlanması, işletmeye özgü yeterli çalışma ve faaliyet standartlarının belirlenmesi ve bunlara uyumun sağlanması gibi konularda işletme yönetimine yardımcı olmaktadır (Türedi vd., 2015: 71). Dolayısıyla, iç denetim sürecinin etkin şekilde yürütülmesi, süreçlerin iyileştirilmesi ve risklerin belirlenerek ilgili önlemlerin alınması önemlilik arz etmektedir. Risk yönetim konusunda başlıca sorumluluk üst yönetime ait olmakla birlikte, iç denetimin risk yönetimi konusunda danışmanlık ve güvence sağlama kapsamında rolü bulunmaktadır. Öte yandan iç kontrol sistemi bileşenlerinden birinin risk değerlendirme olması ve iç

\footnotetext{
${ }^{1}$ FMEA kapsamında Türkiye'de farklı disiplinlerde yapılmış birçok çalışma bulunmakla beraber, bu çalışma kapsamında, "Hata Türü ve Etkileri Analizi (HTEA) ve Denetim" ve "Hata Türü ve Etkileri Analizi (HTEA) ve İç Denetim" anahtar kelimeler çerçevesinde tarama yapılması sonucu herhangi bir çalışmanın mevcut olmadığına ulaşılmışıtır.
} 
denetimin iç kontrol isteminin etkinliği ve yeterliliğini değerlendirme konusundaki sorumluluğu iç denetim, risk yönetimi ve iç kontrol sistemi arasındaki etkileşimi açık şekilde ortaya koymaktadır. Bir işletmede etkin bir iç kontrol sisteminin varlığı etkin bir risk yönetim sürecinin işletmede yerleşmiş olması ile ilişkilidir (Bozkurt, 2010: 26). Özetle, işletmelerin hedeflerine ulaşabilmesinde önemlilik arz eden risk yönetimi konusunda, iç denetimin etkin bir rol üstlendiği gerçeği yadsınamaz. Bu noktada iç denetim faaliyetlerinin etkin bir şekilde yürütülmesinin önemi vurgulanmaktadır.

\section{3. İÇ DENETIMM SÜRECİNI İYILLEŞTİRME VE RİSK YÖNETIMII ARAÇLARI}

İç denetçiler denetim faaliyetlerini yürütürken, bazı temel soruların cevaplarını aramalıdır. Bu sorular ise;

- $\quad$ İşletmeler, iç denetimi uygulama aşamasında ne kadar etkilidir?

- $\quad$ Etkin bir iç denetim yürütmek veya iç denetimi etkili hale getirmek için işletmelerin kullanabileceği bir yaklaşım mevcut mudur?

Bu noktada, Yalın Altı Sigma'nın DMAIC modeli ve bu model kapsamında yer alan "Ölçme" aşamasında yaygın olarak kullanılan araçlardan biri, FMEA devreye girmektedir. Bu aşamada, iç denetimin risk yönetim araçları ile olan ilişkisi tek tek ele alınmıştır.

\subsection{Yalın Altı Sigma Kavramı Ve İç Denetim İle İlişkisi}

Altı Sigma, Motorola mühendisi William Smith tarafından 1980'li yıllarda geliştirilmiştir. 1988'de Motorola, Malcolm Baldrige Ulusal Kalite Ödülü'nü kazandığında Altı Sigma, işletmenin başarısının nedeni olarak tanınmıştır. 1980'ler ve 1990'lar arasında Motorola, Altı Sigma modelinin uygulanması sonucunda 2,2 milyar dolarlık kazanç elde etmiştir. Altı Sigma Motorola'dan sonra General Elektrik başta olmak üzere birçok firmaya gelir artışında fayda sağlamıştır (Taghizadegan, 2010: 3-4; Drohomeretski vd.2014:808). Snee (2000) tarafından Altı Sigma, müşterilerle ilgili faaliyetlere odaklanarak iş süreçlerindeki kusurların veya hataların nedenlerini belirlemeyi ve ortadan kaldırmayı amaçlayan bir iş geliştirme stratejisi olarak ifade edilmektedir. Altı Sigma üretimden personel yönetimine, finanstan pazarlamaya işletmelerin birçok alanında uygulanarak verimliliği sağlamış ve işletmelerin faaliyetlerini karlı şekilde yürütmelerine yardımcı olmuştur ve Altı Sigma kalite odaklidir.

1990’lı y1llarda "Yalın Üretim" kavramı Toyota Üretim Sisteminden esinlenerek James P. Womack tarafından yazılan "Dünyayı Değiştiren Makine” adlı kitapla gündeme gelmiştir. Yalın üretim kaliteyi iyileştirmekten ziyade, her türlü gereksiz israfı azaltmak ve müşterilerin ihtiyaçlarına göre kaynakları kontrol etmeyi ifade etmektedir. Bu iki tekniğin (Altı Sigma ve Yalın Üretim) birlikte ve birbirini destekler şekilde kullanımı daha etkili sonuçların elde edilmesine firsat verecektir (Özveri ve Çakır, 2012: 20). Hostetler'e (2010) göre, "Yalın Altı Sigma, verimliliğe odaklanan yalın üretim konusu ile kaliteye odaklanan Altı Sigma konusunun birleşimidir. Yalın Altı Sigma, bu iki yöntemin dengeli bir yaklaşımıdır. Şekil 1'de bu iki yöntemin ilişkisi sunulmuştur. 


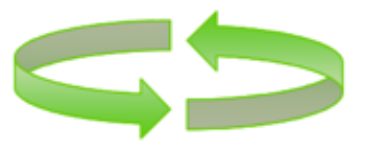

YALIN

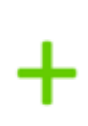

ALTI SİGMA

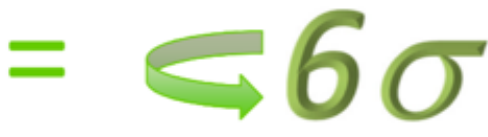

YALIN ALTI SİGMA

Şekil 1. Yalın Altı Sigma Modeli

Kaynak: Anunciacion, 2016: 15

Yalın Altı Sigma yaklaşımının temel amacı, süreç iyileştirme ve varyasyonu azaltmaya odaklanan ölçüme dayalı bir stratejinin uygulanmasıdır. Yalın Altı Sigma, bir dizi kalite yönetimi ve istatistiksel araç kullanarak kusurların nedenlerini (örneğin, hatalar) belirleyip ortadan kaldırarak ve iş süreçlerindeki değişkenliği en aza indirerek süreç çıktılarının kalitesini iyileştirmeyi amaçlamaktadır.

Altı Sigma süreç geliştirmede kullanılan Shewhart'ın PUKÖ (plan-uygulama-kontrolölçme) döngüsünden esinlenerek, DMAIC adı verilen benzer bir yaklaşımı baz almıştır (Montes, 2006: 487). DMAIC, Altı Sigma'nın en güçlü yönünü göstermekte ve aslında Altı Sigma ile aynı anlama gelmektedir. DMAIC, işletmelerin meydan okumaları ve problemleri nasıl saptamaları gerektiği, performanslarını nasıl iyileştirmeleri gerektiğine yönelik tespitte bulunma aşamasında bir yol haritası olarak hizmet etmektedir (Öztürk vd., 2011:395). Bu noktada şunu belirtmekte yarar vardır ki, Yalın Altı Sigma geleneksel Altı Sigma adımları olan DMAIC modelinin adımlarını izlemektedir. Şekil 2'de Altı Sigma- DMAIC modeli adımları sunulmuştur.

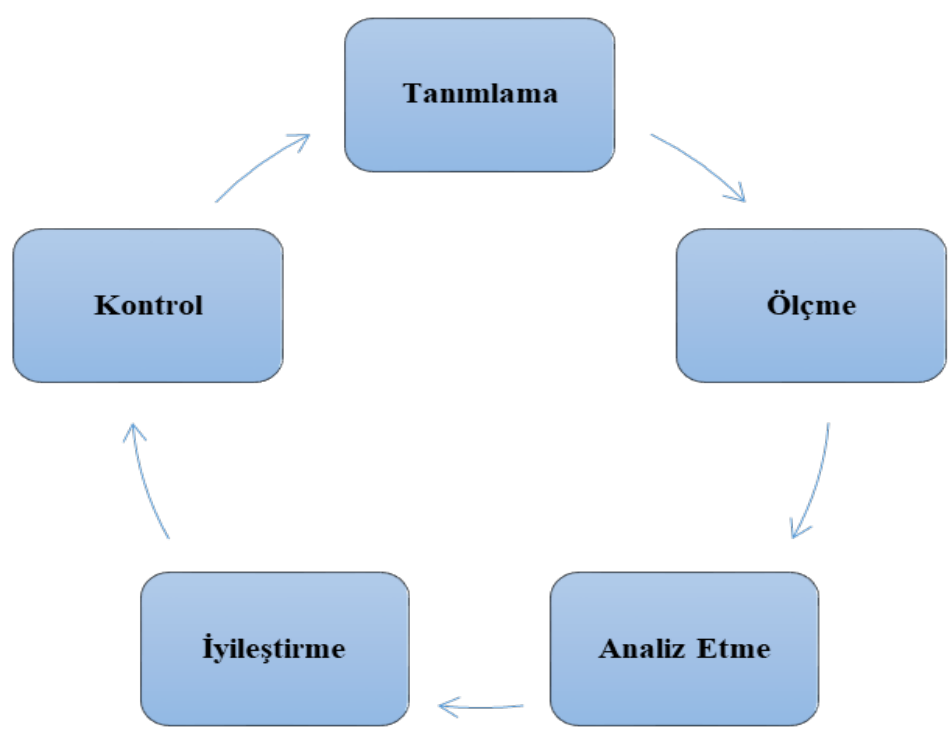

Şekil 2. Altı Sigma-DMAIC Modeli Adımları 
Altı Sigma kavramı, katma değeri olmayan faaliyetleri belirleyip ortadan kaldırarak iş süreçlerinin kalitesini iyileştirmek için uygulanmakta ve sadece üretim sürecini değil, aynı zamanda finansal ve diğer hizmet süreçlerinin de iyileşmesine katkıda bulunmaktadır. $\mathrm{Bu}$ nedenle, bu kavramın iç denetime dahil edilmesi fikri tamamen haklı görünmektedir. Şüphesiz, her iç denetim uygulamasının kendine özgü özellikleri vardır ve bu nedenle Altı Sigma kavramının belirli ilkeleri, iç denetimin tüm süreçlerinde sıkı bir şekilde uygulanamaz. Ancak, faaliyetlerin sürekli izlenmesinde, hataların ve eksikliklerin giderilmesinde, Altı Sigma kavramının temel ilkeleri, en önemli ve uygulanabilir olanıdır. Bu faaliyetler iç denetimin genel kalitesine katkıda bulunmaktadır (Djordjevic vd., 2014: 245). Hafez (2015) tarafindan yürütülen çalışma bu durumu destekler niteliktedir. Çalışma risk yönetimi olan fakat iç denetimde Altı Sigma ve Dengeli Stok Kartı bulunmayan sigorta işletmelerinde yürütülmüştür. $\mathrm{Bu}$ çalışmanın hipotezlerinden biri, Altı Sigma'nın iç denetim etkinliği üzerinde önemli düzeyde pozitif etkiye sahip olacağıdır. Çalışma sonucunda elde edilen bulgular, Altı Sigma'nın ve iç denetimin etkinliği ve verimliliği ile pozitif yönde ilişkili olduğunu doğrulamaktadır.

Tablo 1'de sunulduğu üzere, Altı Sigma, DMAIC performans iyileştirme modeli dahilinde uygulandığında, iç denetimin çeşitli aşamalarına kolayca dahil edilebilmektedir.

Tablo 1.Başarılı İç Denetimin Beş Adımı

\begin{tabular}{|l|l|}
\hline Altı Sigma Aşamaları & İç Denetim Aşamaları \\
\hline Tanımlama & Planlama \\
\hline Ölçme & Uygulama/Yürütme \\
\hline Analiz Etme & Analiz Etme \\
\hline Gelişme/İyileştirme & Tavsiye \\
\hline Kontrol & Takip Etme/İzleme \\
\hline
\end{tabular}

Kaynak: Aghili, 2009: 40

Tablo 1'de, Altı Sigma ve iç denetim aşamalarının her biri ve karşılık gelen çıktılar ele alınmıştır. Böylece Altı Sigma DMAIC modeli ve iç denetim aşamaları kapsamındaki sorumlulukların daha iyi değerlendirilmesine yardımcı olacaktır (Aghili, 2009: 40-43).

Aşama 1: Tanımlama (Denetimin Planlanması): Problemi veya problemli süreci ve ele alınması gereken sürecin temel faktörlerini tanımlamayı içermektedir. Bunlar ölçmek, analiz etmek, iyileştirmek ve kontrol etmektir. İç denetimin ilk aşaması olan "planlama"ya benzer şekilde ele alınmalıdır. Yeterli iç denetim planlaması, iç denetimin önceliklerinin uygulanmasına ilişkin uygun bir karara varılmasına ve ardından ulaşılacak hedeflerin belirlenmesine katkıda bulunmalıdır. Buna ek olarak, iç denetim planı, işletmenin faaliyetlerinin özellikleri hakkındaki bilgilere dayanmalı ve geliştirme stratejisini desteklemelidir. $\mathrm{Bu}$ nedenlerle, Altı Sigma kavramının ilk aşamasının doğru bir şekilde uygulanması ve iç denetim planlaması için sürecin bir haritasının geliştirilmesi tavsiye edilir. Süreç haritalama, olası kusurların ve sorunların daha iyi tespit edilmesini, anlaşılmasını ve değerlendirilmesini sağlamaktadır. Bu aşamada ulaşılması gereken önemli hedefler şunlardır:

- Proje dokümantasyonunun oluşturulması: Odak noktası, iç denetim faaliyetlerinin amacını ve kapsamını tanımlayan, işletmedeki temel faaliyetlerin ve denetime dahil edilecek alanların tanımlanmasını ve bunların belirli kurallara göre önceliklendirilmesini içeren resmi dokümantasyon üzerinedir. Ayrıca, dahil olacak kişilerin sayısını ve niteliklerini 
açıkça tanımlamak, yetkilerini ve sorumluluklarını belirlemek, kaynak talebini değerlendirmek vb. konuların net şekilde belirlenmesi önemlidir.

İşletme yönetimine destek sağlanması: İşletme yönetimi, iç denetim sürecini iş süreçlerinin iyileştirilmesi için önemli olarak algılamaktadır. Bu bakışa sahip yönetim, süreçlerdeki eksiklikleri gidermeye odaklanan iç denetimin tavsiyelerini kabul edecek ve daha fazla iyileştirmenin önündeki engelleri aşmak için daha fazla çaba gösterecektir.

- Proje çıktılarının tanımlanması: Denetim sonuçları belirlenebilir ve ölçülebilir olmalıdır. Bu aşamada Yalın Altı Sigma araçlarının uygulanması sonucunda tasarruf edilen tutar, ölçüdür.

- Proje planının oluşturulması (denetim planı): Çeşitli takım üyelerini de içeren proje planının kapsamı net bir şekilde çerçevesi oluşturulmalıdır.

- Proje ekibinin eğitimi: Denetçilerin Altı Sigma araçlarını ve kavramlarını güvenle kullanmaya başlamalarını sağlamak için yeterli eğitime ve daha sonra sürekli eğitime ihtiyaç vardır. Altı Sigma'nın ilk kez uygulanması aşamasında teknik ve yönetim danışmanı olması tavsiye edilmektedir.

- $\quad$ Süreç haritalarının geliştirilmesi: Potansiyel kontrol zayıflıklarını daha iyi anlamak ve değerlendirmek için süreç haritaları geliştirilmelidir.

Aşama 2: Ölçüm (Denetimin Yürütülmesi/Uygulama): Ölçüm işlevi ölçülen öğe ile diğer öğeler arasında belirli bir ilişkiyi iletme girişiminde sayısal bir atama olarak tanımlar. Bu nedenle, bu ikinci aşama, iç kontrol risklerinin uygunluk derecelerine göre analiz edilmesi, değerlendirilmesi ve sıralanması amaciyla bir dizi finansal veya operasyonel analizlerle başlamaktadır. Örneğin, iç kontrol sistemlerinin etkinliğini ve uygun ölçütlerin uygulanmasını değerlendirirken, iç denetim, işletmelerin her gün karşılaştığı ve iç kontrolün ele alması gereken çeşitli risklerin değerlerini belirleyebilir. 0 ile 5 arasında derecelendirme yapılarak risklerin önem derecesi belirlenir ardından ortaya çıkma olasılığına göre sıralama yapılır. Risklerin önem dereceleri ve ortaya çıkma olasılıklarının belirlenmesi aşamalarında aşağıdaki sorulardan yola çıkılarak bir değerlendirme yapılabilir. Bunlar:

- $\quad$ Mevcut kontroller ne kadar etkilidir?

- Mevcut kontroller ne zaman başarısız oldu? Neden başarısız oldu? Başarısızlık sonucu tahmini kayıp nedir? nedeni nedir?

- $\quad$ Geçmiş birkaç yıl içerisinde kontroller ne sıklıkla başarısız oldu? Başarısızlık

- Değerlendirilen kontrol yönetimi ile ilgili bir alan mıdır?

- $\quad$ Kontrol başarısızlığı kar-zarar tablosunu nasıl etkiledi?

Değerlendirmenin yapılmasının ardından riskin önem sırası ve ortaya çıkma olasığı çarpılarak her kontrol önlemi için bir risk değeri belirlenir. Sonrasında riskler önem sırasına göre sıralanarak zayıf noktalara doğru şekilde odaklanılması sağlanır. Bu aşamadaki temel düşünce, riskleri sıralayarak etkin olmayan kontrollerin belirlenmesi ve kaynakların boşa harcanmasının önlenmesidir.

Aşama 3: Analiz Etme (Analiz Etme): Üçüncü aşamada sapmaların nedenlerini bulmak ve bunların süreç performansı üzerindeki etkisini değerlendirmek amacıyla elde edilen sonuçlar analiz edilir. İç denetçiler, mevcut sistemin durumunu daha iyi anlamalarını sağlayan testler yaparlar. Bu noktada iç denetçi planlandığ gibi çalışmayan prosedür, kural ve 
düzenlemelere uygun olmayan iç kontrol sistemini incelemektedir. Ayrıca, nicel testlerin uygulanmasıyla iç denetçi iç kontrol sisteminin bir kısmının çıktı kalitesine yeterince yansitılmayan etkisini belirleyebilir. Bunu yaparken, çeşitli veri sunumu, analizi ve anket araçları kullanılabilir (Djordjevic vd., 2014: 247).

Aşama 4: Gelişme/İyileştirme (Tavsiye): Ölçüm ve analiz aşamalarının dikkatli bir şekilde uygulanmasının ardından, dördüncü aşamada denetçi, süreç iyileştirme firsatlarını belirleyebilmeli ve sapmaları (hatalar, ihmaller, vb.) ortadan kaldırmak için öneriler sunabilmelidir. Bu tavsiyeler, iç denetçinin raporunda yer alır ve mevcut koşulları düzeltmek veya işlemleri iyileştirmek için harekete geçme çağrısı yapar ve istenen sonuçlara ulaşmada yönetim için bir kılavuz olarak performansı düzeltmeye veya artırmaya yönelik yaklaşımlar önerebilir.

Aşama 5: Kontrol (Takip Etme/İzleme): Son aşama, ilk dört aşamada yapılan değişikliklerin sonucunda elde edilen kazanımların korunması ile ilgilidir. İç denetim kavramını karşılayacak şekilde bu aşamada iç denetçiler tarafından, raporlanan gözlemler ve tavsiyeler üzerine yönetim tarafından alınan önlemlerin yeterliliği, etkililiği ve zamanlaması takip edilerek değerlendirilir. Bunu yaparken denetçiler, yönetim tarafindan tavsiyelerin kabul edildiğini ve uygulanmasını gösteren verileri çeşitli şekillerde toplayabilir ve analiz edebilir. Bu işlemler, tavsiyelerin uygulanmasından sorumlu personel ile görüşme, destekleyici belgelerin gözden geçirilmesi, alınan önlemlerin etkinliğini belirlemek için testler yapılması vb. şeklinde sıralanabilir (Djordjevic vd., 2014: 247).

Altı Sigma işletmelerin sorunların temel nedenlerini belirlemek ve düzeltmek için daha doğru ve niceliksel bir yaklaşım benimsemelerini sağlayan güçlü bir araç setini ifade eder. Böylelikle, iç denetim ekibinin daha etkili denetim tavsiyeleri vermesine olanak tanır. $\mathrm{Bu}$, uyumlulukla ilgili maliyetleri düşürmeye ("Yalın" etkisi) ve bir işletmenin iç kontrollerinin etkinliğini (Altı Sigma etkisi) geliştirmeye yardımcı olur. Bu nedenle, tüm Yalın Altı Sigma ve iç denetim projelerinin amacı, kuruma değer katmayan harcamalardan kaçınarak iç kontrolleri iyileştirmektir. Burada sunulan DMAIC modeli, çeşitli iç denetim projelerine dahil edilebilecek genel bir çerçeve görevi görür (Aghili, 2009: 38).

İç denetim sürecinde Yalın Altı Sigma ilkesinin uygulanması, işletmedeki süreçlerin daha iyi anlaşılması ve gelişmesi için firsatlarının belirlenmesine olanak sağladığından, işletme süreçlerinin etkinliğini artırmak için büyük önem taşımaktadır. Bu önem, iç denetimin teori ve pratiğinin gelişimi için en güçlü etkiye sahip uluslararası bir dernek olan İç Denetçiler Enstitüsü tarafından kabul edilmiştir. Bu bağlamda Enstitü 2017 yılında Yalın Altı Sigma metodolojisi, denetimin planlanmasında ve gerçekleştirilmesinde kullanılabilecek araçların temelini sunmak amacıyla çeşitli kurs ve eğitimler düzenlemiştir. Eğitimlerin amacı, Yalın Altı Sigma metodolojisi ile iç denetim standartları arasındaki ilişkiyi açıklamak, DMAIC metodolojisini iç denetimin beş aşamasına bağlamak, işletmede süreç haritasının gerekliliğini ve önemini vurgulamak, amaç ve yöntemi, çeşitli analiz araçlarının uygulanması ve benzerlerini açıklamaktır (IIA, 2017: 1).

Sonuç olarak DMAIC modeli, iç denetim standartlarıyla uyumlu, disiplinli, risk temelli bir yaklaşım olarak hizmet etmektedir. Denetim ekibine, temel nedenleri daha iyi saptamak, uyumsuzluk alanlarını ölçmek ve belgelemek ve işletme giderlerini azaltmanın yollarını önermek için araçlar sağlamaktadır. Ayrıca, çeşitli araştırmaların sonuçları, bir 
işletmenin kontrol sistemleri daha etkili hale geldiğinde, sermaye getirisinin iyileştiğini göstermektedir.

\subsection{Hata Türü Ve Etkileri Analizi, İç Denetim İle İlişkisi}

Hata Türü ve Etkileri Analizi (FMEA) ABD tarafından 1950'li yılların başında uçuş kontrol sistemlerinde kullanılmaya başlanmış ve 1960'tan sonra havacilıkta sistemli olarak uygulanmış olmakla birlikte, NASA tarafından 1960-1965 yılları arasında aya insan indirme (APOLLO) projesinde denenmiştir. Daha sonrasında ABD'de Silahlı Kuvvetlerde kullanılmıştır. Endüstri'de ilk kullanımı Japon NEC firması tarafindandır. Bugün, otomotiv, tekstil vb. alanlarda kullanılmaktadır (Akın, 2005: 271-272).

FMEA, süreç veya ürün hatalarının oluşmadan önce tanımlanmasını ve önlenmesini sağlayan proaktif bir araç, teknik ve kalite yöntemidir. Altı Sigma metodolojisine gömülü bir araç olarak FMEA, bir sürecin veya yeni hizmet sunumunun geliştirilmesinin ön aşamalarında hataları belirleyip ortadan kaldırmaya yardımcı olabilir. FMEA Altı Sigma'nın DMAIC modeli kapsamında yer alan "Ölçme" aşamasında yaygın kullanılan araç kapsamındadır (Duru vd. 2011: 57). Başarısızlığın meydana gelebileceği olası yollar için bir süreci ileriye dönük olarak incelemenin ve ardından süreçleri yeniden tasarlamanın sistematik bir yoludur, böylece yeni modelde başarısızlık olasılığını ortadan kaldırır. Doğru bir şekilde uygulandığında, FMEA genel memnuniyet ve güvenlik seviyelerinin iyileştirilmesine yardımcı olabilir (Smith, 2004). Diğer bir ifadeyle FMEA, sürekli iyileştirme ve risk yönetiminin bir parçasıdır. FMEA ürün ve süreç geliştirmenin önemli bir kısmını oluşturmaktadır. Aynı zamanda, ürün ve süreç geliştirmenin tamamında olası hataları değerlendirme ve riski azaltacak uygulamaları gerçekleştirmeyi sağlamak için kullanılan uzun süreli bir çalışmadır (Down vd., 2008: 5). Birkaç güvenilirlik değerlendirme ve tasarım analizi araçlarından biri olan FMEA ayrıca şu şekilde tanımlanabilir:

- Sürecin zayıf alanlarını belirlemek ve bunların oluşmasını önlemek için planlar geliştirmek için kullanılan bir problem önleme aracıdır.

- $\quad$ Bir ekip tarafından yürütülen yarı niceliksel, tümevarım yaklaşımıdır.

- $\quad$ Bir sürecin kritik müşteri gereksinimlerini karşılamada başarısız olabileceği yolları belirlemek için yapılandırılmış bir yaklaşımdır.

- $\quad$ Süreçteki hatalarla ilgili belirli nedenlerin riskini tahmin etmenin bir yoludur.

- Arızaların oluşmasını önlemek için mevcut kontrol planını değerlendirmek için bir yöntemdir.

- Durumu iyileştirmek için alınması gereken eylemler için bir önceliklendirme sürecidir (Smith, 2004).

FMEA uygulamasında üç önemli bileşenin çarpımıyla Risk Öncelik Sayısı (RÖS) hesaplanmaktadır. Bu bileşenler sırasıyla olasılık, şiddet ve saptama/farkedilebilirliktir. Olasılık tehlikenin/hatanın gerçekleşme sıklığını anlamına gelmektedir. Şiddet hatanın gerçekleşmesi durumunda ne kadar etki yaratacağını gösteren derecedir. Saptama/Farkedilebilirlik ise bu tehlikenin gerçekleşmeden önce ne derecede saptanabileceğinin ölçüsüdür. RÖS değeri hesaplanırken öncelikle yukarıda bahsedilen üç değere 1-10 arasında puanlama yapılır ardından bu puan birbirleri ile matematiksel olarak çarpımı ile RÖS değeri elde edilmektedir. Dolayısıyla RÖS değeri sonuçları [1, 1000] 
arasındaki değerlerden oluşmaktadır (Aydan ve Kaya, 2017: 486). Bir hata türüne ait RÖS değeri ne kadar büyük olursa, hatanın gerçekleşme riski artacağından dolayı hata türüne yönelik hızlı şekilde önleyici tedbirlerin alınması gerekmektedir (Şişman, 2017: 235).
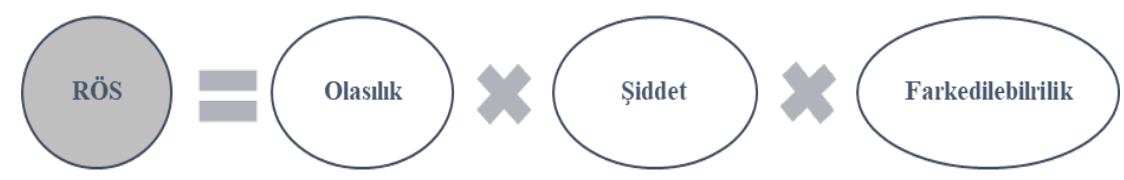

RÖS değerini yorumlanırken RÖS değeri 40'ın altında olan riskler için önlem alma gerekliliği yoktur. RÖS değeri 40 ile 100 arasında olması halinde işletmenin kararına bağlı olarak risklere karşı önlem alınabilir. RÖS değeri 100'ün üstünde olması halinde riskler mutlaka gözden geçirilme ve gerekli proaktif ve reaktif önlemler alınmalıdır. Bu noktada RÖS değerinin üç bileşeni olan; olasılık, şiddet ve sapma değerleri düşürülmelidir. Yeni durum için RÖS değerleri hesaplanmalıdır. Sistemde mevcut riskler gerçekleştiği zaman bu hata yeniden gözden geçirilmeli, gerekli önlemler alınmalıdır. Görüldüğü üzere FMEA sonlu bir analiz değildir. Sistemi sürekli kontrol altında tutması, olası bir kaza gerçekleştiğinde gerekli önlemleri alarak analizi tekrarlaması, gelişen teknoloji ve koşullara göre sistemin karşılaşacağı yeni riskleri ve hataları tanımlayarak bunlar için de analizlerin gerçekleştirilmesini kapsamaktadır (Özfırat, 2014: 757). FMEA kavramına ilişkin genel açıklamalarının ardından bu metodun uygulama adımları Şekil 3'teki gösterildiği üzere on üç adımdan oluşmaktadır (Çeber, 2010, 54-70):

\begin{tabular}{|c|}
\hline FMEA Kapsammm Belirlenmesi \\
\hline FMEA Takımmm Kurulması \\
\hline FMEA Uygulanacak Sürecin İncelenmesi \\
\hline Beyin Firtınası ve Olası Hata Türlerinin Belirlenmesi \\
\hline Olası Hata Nedenlerinin Belirlenmesi \\
\hline Olası Hata Etkilerinin Belirlenmesi \\
\hline Mevcut Kontrollerin Belirlenmesi \\
\hline Ortaya Çlkma Değerinin Belirlenmesi \\
\hline Şiddet Değerinin Belirlenmesi \\
\hline Saptama Değerinin Belirlenmesi \\
\hline Risk Öncelik Sayısının (RÖS) Hesaplanması ve Değerlendirilmesi \\
\hline Alınacak Önemlerin Belirlenmesi ve Uygulanması \\
\hline FMEA Uygulamasından Sonra Yeni RÖS Değerinin Hesaplanması \\
\hline
\end{tabular}

Şekil 3. FMEA Uygulama Aşamaları 
- FMEA Kapsamının Belirlenmesi: Çalışmanın sınırları belirlenmelidir. FMEA'nın hangi alanda uygulanacağı; hangi süreç veya hizmetin değerlendirileceği tam olarak tanımlanmalıdır. FMEA uygulaması herkes tarafından anlaşılacak şekilde net şekilde ve uygulamaya özel şekilde tanımlanmalı ve kayıt altına alınmalıdır.

- $\quad$ FMEA Takımının Kurulması: FMEA uygulanacağı süreç hakkında uzman kişilerden oluşan bir ekip kurulmalıdır. Bu takım kapsamında FMEA uygulanacak sürece ilişkin tüm detaylar paylaşılmalıdır. Takım çalışmasının sergilenmesi gerekliliği tüm süreçlere ilişkin girdilerin ve takım koordinasyonunun sağlanmasından kaynaklıdır. Takımlar FMEA'lara özel oluşturulurlar (Down vd., 2008:9). Sabit bir FMEA ekibinden söz etmek mümkün değildir

- FMEA Uygulanacak Sürecin İncelenmesi: İşletmelerde uygulanacak tüm yaklaşımlarda ileriye dönük kararların doğru şekilde alınması adına öncesinde yapılması zorunlu olan mevcut sürece ilişkin tespitlerin yapılmasıdır. FMEA uygulaması içinde bu durum geçerlidir. FMEA uygulanacak süreci kapsayan fonksiyonlar, alt sistemler ve bileşenler belirlenerek bu sürece ait tüm dokümantasyonlar detaylıca incelenmelidir (Sellappan ve Sivasubramanian, 2008). Bu amaçla geriye dönük kayıtlar, süreç akış şemaları, formlar kullanılabilir. Tüm takımın üyeleri kendi süreci ile birlikte diğer süreçleri takip etmeli ve bilgi sahibi olmalıdırlar.

Beyin Fırtınası ve Olası Hata Türlerinin Belirlenmesi: Olası hata, sistemde meydana gelmesi muhtemel olan fonksiyon yetersizlikleridir. Mevcut durumda var olmayan fakat oluşması muhtemel hatalar için kullanılır. Sistem incelenirken geçmişte meydana gelmiş, mevcut ve gelecekte oluşabilecek hataların hepsi göz önünde bulundurulmalıdır. $\mathrm{Bu}$ aşamada gelecekte meydana gelme olasılığg olan hata türleri belirlenirken "ne yanlış olabilir" sorusu sorularak süreç yürütülmelidir. Bu aşamada sitemde oluşabilecek muhtemel hatalar belirlenirken kullanılan en kolay yöntem olarak beyin fırtınası tekniği önerilmektedir. FMEA süreci incelendikten sonra takımda bulunan tüm üyelerin katılacağı düzenli toplantılar düzenlenerek takımdaki uzman alanında uzman kişiler tarafından olası hata olarak düşünülen her fikir takım ile paylaşılmalıdır.

- Olası Hata Nedenlerinin Belirlenmesi: Olası hata nedeni, hatanın nelerden nasıl oluşabileceğini belirtir. Hata ile nedeni arasında doğrudan bir bağlantı vardır ve "eğer...olursa, ... olur" kalıbını benimsenmesi olası hataların nedenlerinin bulunmasında yardımcı olacaktır. Hata türünün nedeninin belirlenmesi uygun kontrol ve eylem planlarının tanımlanmasını sağlamaktadır (Down vd., 2008:12).

- Olası Hata Etkilerinin Belirlenmesi: Potansiyel hata etkilerinin belirlenmesi, hataların sonuçlarının ve bu sonuçların ciddiyeti veya şiddeti analizini kapsamaktadır (Down vd. 2008:12)

- Mevcut Kontrollerin Belirlenmesi: İşletmelerin halihazırda uyguladıkları kontroller süreçteki bazı hataların oluşmasını engellemekte veya oluşmuş olan hataların düzeltilmesinde yardımcı olmaktadır. Bu aşamada FMEA uygulama sürecinde kontrol amaçlı işlemler belirlenmelidir. Kontrol işlemlerine ilişkin incelemelerin yapılması aşamasında veya yeni bir kontrol işlemlerine yönelik planlar yapılırken, hatanın oluşmasını engelleyecek yönde işlemlerin tasarlanması önemlilik arz etmektedir. Bu bakış açısıyla oluşturulmuş işlemler ile zaman, iş gücü ve malzeme tasarrufu sağlanarak işletme kaynaklarının boşa kullanımının önüne geçilecektir. Tüm bu çalışmalar sonucunda FMEA uygulaması içinde "olasılık" değerinin düşürülmesi de sağlanmış olacaktır. 
- Ortaya Çıkma Değerinin Belirlenmesi: Hatanın ortaya çıkma sıklığını gösterir ve her bir olası hata türünün gerçekleşme olasılığıyla ilgilidir (Durhan, 2009: 35). Bu değere hatanın frekansı da denir (Chang\&Sun, 2009: 630).

- Şiddet Değerinin Belirlenmesi: Şiddet değeri, hataların olma ihtimalinde işlemeyi nasıl etkileyeceği ile ilgilidir (Ulu\&Şahin,2020: 67). Şiddet değeri belirlenirken yine takımın deneyimlerinden ve geçmişe dönük kayıtlardan faydalanılır.

- Saptama Değerinin Belirlenmesi: Saptama değeri, işletmenin mevcut kontrolleriyle gerçekleşen hataların bulunarak engellenmesi yeteneğini ifade etmektedir. Diğer bir ifadeyle kontrol yöntemlerinin uygunluk ve etkinlik açısından değerlendirilmesidir. Bu noktada işletmelerin fazla sayıda kontrollere sahip olması hatalar ile karşılaşma olasılığını azalmasına rağmen zaman ve maliyet açısında işletmeye ayrıca bir yük getirmesi sebebiyle işletmelerin hataların ortaya çıkma olasılığını azaltamaya odaklanmaları daha etkili olacaktır. (Erginel, 2004:25). Bu noktada kontrollerin listelenip etkinliği değerlendirilmelidir.

- $\quad$ Risk Öncelik Sayısının (RÖS) Hesaplanması ve Değerlendirilmesi: RÖS, hatanın oluşma olasılığı (P), şiddet (S) ve saptama (D) değerlerinin çarpımıyla elde edilir. Risk öncelik sayısı değerinin FMEA çalışması boyunca belirlenen tüm potansiyel hataların azalan şekilde sıralanmasını sağlamaktadır. $\mathrm{Bu}$ sıraya göre en fazla risk teşkil eden hata türleri belirlenir ve iyileştirilmesi gereken alanların hangisine öncelik verilmesi konusunda yardımcı olmaktadır. Bu iyileştirme çalışma için RÖS değeri için bir sınır belirlenmelidir. Hesaplanan RÖS değerlerinde dikkat edilmesi gereken bir diğer konuda farklı hataların aynı RÖS değerine sahip olma halidir. Bu noktada şiddet değeri yüksek olan RÖS değerine öncelik verilir. Çünkü bu değer hatanın etkisini göstermektedir. Şiddetten sonra saptama değeri baz alınır.

- Alınacak Önemlerin Belirlenmesi ve Uygulanması: RÖS değeri daha önceden belirlenmiş olan sınır değerini aşması halinde hatalar için RÖS değerini azaltacak şekilde önlemler alınmalıdır. Bu iyileştirme çalışmaları ile RÖS değerleri aşağıya düşürülmeye çalışılmaktadır. Ortaya çıkma, saptama ve şiddet değerleri küçültülerek RÖS değeri aşağıya çekilmiş çalışılır. İyileştirme faaliyetlerinin belirli bir süre içinde tamamlanması ve sonuçların üst yönetime bildirilmesi gerekir.

- FMEA Uygulamasından Sonra Yeni RÖS Değerinin Hesaplanması: FMEA uygulaması kesintili bir süreç yapısına sahip olmaması itibariyle belirlenen önlemlerin uygulanmasından sonra, önlemlerin alınmasından önceki durum ile karşılaştırmak adına gerçekleşmesi muhtemel hatalar için yeni bir RÖS değeri hesaplanır. Böylece hataların başlangıç değerin ne kadar altında düştügü hesaplanmış olur. FMEA ekibi tarafından belirlenen sınır değere ulaşılması ile birlikte uygulamanın başarıya ulaşmıştır.

Özetle FMEA'nın diğer risk değerlendirme ve ölçme araçlarından en önemli farkı ve üstünlüğ̈̈, sistemde bir problem meydana geldikten sonra çözüm üretmesi değil, olabilecek problemleri önceden tanımlaması ve onlara karşı önleyici tedbirler geliştirmesidir. Bu açıdan FMEA'nın, hata türlerini önceliklendirmek için yararlı ve etkili bir yol sağladığı söylenebilir (Liu vd., 2014:257).

İç denetim ve FMEA arasında iki yönlü bir ilişki olduğu söylenebilir. Bunlardan ilki iç denetim, risk odaklı yaklaşıma doğru yönelmiş olması ile birlikte risk yönetiminin çıktılarını kullanarak denetimde yüksek riskli alanları seçmektedir. Bu sayede denetimde etkinliğin artırılması, maliyet ve zaman tasarrufunun sağlanmaktadır (Kishali ve Pehlivan, 2006: 76). Risk odaklı iç denetim iç kontrol sistemi ve kurumsal risk yönetimi yapısının 
tasarlanması ve faaliyetlerin işletme hedefleri doğrultusunda yürütülmesi, işletmede riskli görülen alanlarının sürekli izlenmesini ve yönetime önerilerin sunulmasını kapsamaktadır (Türedi vd., 2015:17). FMEA'nın bu yaklaşımı destekler şekilde sürekli şekilde işletme faaliyetlerini iyileştirme yönelik riskleri tespit ederek ve gerekli kontrollerin yeterliliği konusunda tespitlerde bulunduğu görülmektedir. Dolayısıyla risk odaklı bir iç denetim anlayışa sahip işletmelerin FMEA yaklaşımını kullanmaları halinde kurum ya da işletmede tüm faaliyet ve uygulamaların, etkin ve verimli şekilde yürütülmesi konusunda yardımcı olan bir yaklaşım olduğu söylenebilir.

FMEA'nın uygulama adımlarına bakıldığında temel anlamda risk değerlendirmeye odaklandığı dolayısıyla COSO İç Kontrol- Bütünleşik Çerçeve bileşenlerinden risk değerlendirme aşamasına hizmet ettiği söylenebilir. Ayrıca FMEA'nın "Mevcut Kontrollerin Belirlenmesi" ve "Alınacak Önlemlerin Belirlenmesi ve Uygulanması" aşamaları göz önünde tutulduğunda iç denetimin iç kontrol sisteminin etkinliği konusunda yönetime danışmanlık hizmeti vermesi bu aşamalara katkı sağladığı yönündedir. Çünkü FMEA kapsamında özellikle mevcut kontrollerin belirlenmesi aşamasında iç kontrol sistemi devreye girdiği söylenebilir. $\mathrm{Bu}$ aşamada iç kontrol sistemin etkin şekilde kurulması ve yürütülmesi hatanın oluşmasını önleyecek kontrollerin göstergesidir. Etkin iç kontrol sisteminin varlı̆̆ hata oluşma olasılığının düşük çıkması ve RÖS değerinin azalması yönünde katkı sağlayacağı şeklinde yorumlanabilir.

FMEA'nın temel amacı, gözden geçirilmekte olan süreçle ilgili çeşitli riskleri değerlendirmektir. Bunun denetimle nasıl bir ilişkisinin var olduğu konusunda diğer bir nokta ise iç denetimin ne kadar etkin olduğu, etkin değilse işletmelerin ne tür risklerle karşı karşıya kalacağı konusu, işletmeye maliyetinin neler olacağı konuları kapsamındadır. Bu konular çerçevesinde, FMEA süreçteki potansiyel risklerin şiddeti, oluşumu ve tespiti temelinde değerlendirmelerin yapılmasında yardımcı olması olduğundan, iç denetim sürecinin iyileştirilmesinde etkili bir yaklaşım olduğu söylenebilir (Munro, 2014).

\section{SONUÇ}

İşletmeler, iç denetim programının bir parçası olarak sistemi sorgulama ve riskleri azaltmak için süreç yaklaşımını kullanma becerilerini sürekli olarak geliştirmelidir. $\mathrm{Bu}$ noktada, çalışmada iç denetimde süreçleri iyileştirmek için Yalın Altı Sigma ve Yalın Altı Sigma metodolojisine gömülü olan FMEA aracı önerilmiştir.

Yalın Altı Sigma modeli, iç denetim standartlarıyla uyumlu, disiplinli, risk odaklı bir yaklaşım olarak karşımıza çıkmaktadır. Bu yaklaşım, süreç iyileştirme ve maliyet azaltmaya odaklanan ölçüm tabanlı bir stratejinin uygulanmasıdır. Altı Sigma, bir dizi kalite yönetimi ve istatistiksel araç kullanarak hataların nedenlerini belirleyip, bunları ortadan kaldırarak ve iş süreçlerindeki değişkenliği en aza indirerek, süreç çıktılarının kalitesini iyileştirmeyi amaçlamaktadır. $\mathrm{Bu}$ aşamada, iç denetimin planlama ve saha çalışması aşamalarında denetimin etkinliğini artırmak, iş süreçleri hakkında daha derin görüş sağlamak ve süreci kolaylaştıran fırsatları belirlemek için kullanılabilecek bazı temel Yalın Altı Sigma araçları devreye girmektedir. Bu araçlar, bağımsız olarak veya mevcut denetim yöntemleri, araçları ve teknikleriyle bağlantılı olarak kullanılabilir. İşletmeye değer katmayan maliyetlerin azaltmasına ve sistem ve süreçlerde karşılaşılan riskleri değerlendirmesine yardımcı 
olmaktadır. Ayrıca, işletmeye sağlanan bu faydalarla uyum ve kontrol sistemleri daha etkili hale gelmekte ve süreçlerin iyileştirilmesine fayda sağlamaktadır.

FMEA modeli, başarısızlı̆̆ı meydana gelebileceği yolları incelemektedir. $\mathrm{Bu}$ incelemelerin temelinde riskli alanların belirlenmesi ve bu riskli alanlara ilişkin proaktif şekilde önlemlerin alınmasını içermektedir. FMEA'nın hem iç denetimin kendi denetim faaliyet sürecinin değerlendirilmesi, hem de iç denetim faaliyetinin yürütüldüğü ilgili alanda iyileştirmelerin sağlanması için danışmanlık görevinin yürütülmesinde fayda sağlayacağı söylenebilir. Bir iç denetimin planlama aşamasında denetim etkinliğini artırmak, iş operasyonları hakkında daha derin bilgiler sağlamak ve süreç düzenleme firsatlarını belirlemek için Yalın Altı Sigma araçları kullanılabilmektedir. Bu araçlar bağımsız olarak veya mevcut denetim metodolojileri, araçları ve teknikleri ile birlikte kullanılabilir. İç denetçilerin, araç ve teknikleri denetim faaliyetlerine entegre etmeleri sağlanmalıdır.

FMEA uygulama süreci incelendiğinde zamandan ve aynı risk faktörünü birkaç kez farklı bir kapsamda analiz etmekten kaçındığı için etkili bir yaklaşım olarak değerlendirilebilir.

Süreçlerin iyileştirilmesinde kullanılan birçok yaklaşım olmakla birlikte çalışmada iki yaklaşım önerilmiştir. Bu yaklaşımlar özellikle iş süreçlerinin verimliliğine, etkililiğine ve tutumluluğuna odaklanan iç denetim, risklerin değerlendirmesi, süreçteki zayıflıkları belirlemesi ve iyileştirilmesi için tavsiyelerde bulunmaktadır. Bu sayede, işletme hedeflerinin gerçekleştirilmesine, işletmeye değer katarak ve uzun vadeli faydalar yaratarak katkıda bulunmaktadır. Bu iki yaklaşım yaygın şekilde mühendislik alanında kullanılmakla birlikte birçok alanda uygulamaları mevcuttur. Yalın Altı Sigma-DMAIC modeli ve FMEA'nın iç denetim üzerinde olumlu etkileri göz önünde bulundurulduğunda ilerleyen çalışmalarda denetimle ilintili olarak ele alınması alan yazına katkı sağlayacaktır.

\section{KAYNAKLAR}

Aghili, Shaun (2009), “A Six Sigma Approach to Internal Audits”, Strategic Finance, 90 (8), pp. 38-43.

Akın, H. Besim (2005), "Hata Türü ve Etkileri Analizi (FMEA) ve Bir Uygulama", Öneri Dergisi, 6(24), ss.271-278.

Anunciacion, Ernest (2016), Incorporating Lean Six Sigma into the Internal Audit Process. http://www.dallasiia.org/wp-content/uploads/2016/10/Lean-Sigma-Anunciacion.pdf (Erişim Tarihi: 05.03.2021).

Aydan, Murat - Kaya Sıdıka (2017), "Hata Türü ve Etkileri Analizi (HTEA): Üniversite Hastanesinde Bir Uygulama”, Hacettepe Sağlık İdaresi Dergisi, 20(4), ss.475-502.

Bozkurt, Cevdet, (2010), "Risk, Kurumsal Risk Yönetimi ve İç Denetim”, Denetişim, (4), ss.17-30. 
Chang, Dong-Shang-Sun, Kuo-Lung Paul (2009), “Applying DEA to Enhance Assessment Capability of FMEA”, International Journal of Quality \& Reliability Management, 26(6), pp.629-643.

Choo, Bennie Seck Yong - Goh, Jenson Chong-Leng (2015), "Pragmatic Adaptation of the ISO 31000: 2009 Enterprise Risk Management Framework in a High-Tech Organization Using Six Sigma”, International Journal of Accounting \& Information Management, 23(4), pp.364-382.

Çeber, Yasemin (2010), Hata Türü ve Etkileri Analizi Yönteminin (FMEA) Üretim Sektöründe Uygulanması, Yüksek Lisans Tezi, DEÜ Sosyal Bilimleri Enstitüsü.

Djordjevic, Milica - Cecevic, Bojana Novicevic (2014), "Synergistic Effects Of Internal Audit And Lean-Six Sigma Concept On Business Process Improvement”, Facta Universitatis, Series: Economics and Organization, 11 (3), pp. 237-249.

Down, Michael-Brozowski, Lawrence-Younis, Hisham-Benedict, David-Feghali, JohnSchubert, Michael-Brender, Rhonda-Gruska, Gregory-Vallance, Glen-Krasich, Milena- Haughey, William (2008), "Potential Failure Mode and Effect Analysis (FMEA)”, Chryler LLc, Ford Moyor Company, General Motors Corportion, https://www.academia.edu/26573569/POTENTIAL_FAILURE_MODE_AND_EFFE CTS_ANALYSIS_FMEA_Reference_Manual_Fourth_Edition, (Erişim Tarihi: 01.06.2021).

Drohomeretski, Everton- Gouvea da Costa, Sergio E- Pinheiro de Lima, Edson- Garbuio, Paula Andrea da Rosa (2014), "Lean, Six Sigma and Lean Six Sigma: an analysis based on operations strategy”, International Journal of Production Research, 52(3), pp. 804-824.

Durhan, Dilan (2006), "Hata Türü ve Etkileri Analizi (FMEA) ve Bir Uygulama, Yüksek Lisans Tezi, Gazi Üniversitesi, Fen Bilimleri Enstitüsü, Ankara., https://tezarsivi.com/hata-turu-ve-etkileri-analizi-fmea-ve-bir-uygulama, (Erişim Tarihi: 01.06.2021)

Duru, Nafiz- Koç K. Hüseyin- Taş Yüksel (2011), "İşletmelerde Hatasızlığa Yönelim, Altı Sigma ve Hata Türü Etkileri Analizi”, Düzce Üniversitesi Orman Fakültesi Ormancılık Dergisi, 7(1), ss.56-67.

Erginel, M. Nihal (2004), “Tasarım Hata Türü Ve Etkileri Analizinin Etkinliği İçin Bir Model Ve Uygulaması”, Endüstri Mühendisliği, 15(3), ss.17-26.

Hafez, Samah (2015), “The Integration Of Six Sigma And Balanced Scorecard in Internal Auditing”, Research Journal of Finance and Accounting, 6 (18), pp. 43-54.

Hostetler, Dustin (2010), “Get Results: Improve Your Accounting Firm Processes Using Lean Six Accountancy, https://www.journalofaccountancy.com/issues/2010/jan/20091484.html, (Erişim Tarihi:13.04.2021) 
Kishali, Yunus- Pehlivanli. Davut (2006), “Risk Odaklı İç Denetim ve İMKB Uygulaması”, Muhasebe ve Finansman Dergisi, 30, ss.75-87.

Liu, Hu Chen-You, Jian-Xin-You, Xiao-Yue (2014), "Evaluating the Risk Of Healthcare Failure Modes Using Interval 2-tuple Hybrid Weighted Distance Measure”, Computers \& Industrial Engineering, 78, pp.249-258.

Montes F. Javier Lloréns-Molina, Luis M. (2006), "Six Sigma and Management Theory: Processes, Content And Effectiveness", Total Quality Management and Business Excellence, 17(04), pp. 485-506.

Munro, Roderick A. (2014), “Internal Audits Using Risk Assessment”, https://www.theauditoronline.com/internal-audits-using-risk-assessment/ (Erişim Tarihi: 03.03.2021).

Özfirat, Pınar Mızrak (2014). "Bulanık Önceliklendirme Metodu Ve Hata Türü Ve Etkileri Analizini Birleştiren Yeni Bir Risk Analizi Yöntemi”, Gazi Üniversitesi Mühendislik Mimarlık Fakültesi Dergisi, 29(4), ss. 755-768.

Öztürk, Ahmet-Arıkan, V. Sinem-Öztürk, M. Umut (2011), "Süreç İyileştirme Yöntemleri ve Yöneylem Araştırması", Atatürk Üniversitesi İktisadi ve İdari Bilimler Dergisi, 10. Ekonometri ve İstatistik Sempozyumu Özel Sayısı, ss. 391-405

Smith, Deborah L. (2004), "FMEA: Preventing A Failure Before Any Harm Is Done”, https://www.isixsigma.com/tools-templates/fmea/fmea-preventing-failure-any-harmdone/, (Erişim Tarihi: 01.06.2021)

Snee, Ronald D. (2000), “Impact of Six Sigma on Quality Engineering”, Quality Engineering, 12(3), pp. 9-14.

Sellappan, N., Sivasubramanian, R., (2008), "Modified Method for Evaluation of Risk Priority Number in Design FMEA”, Icfai University Press. India (Aktaran Yasemin Çeber, (2010), Hata Türü ve Etkileri Analizi Yönteminin (FMEA) Üretim Sektöründe Uygulanması, Yüksek Lisans Tezi, DEÜ Sosyal Bilimleri Enstitüsü, ss.57)

Şişman, Bilal (2017), "Hata Türü Ve Etkileri Analizinde Bulanık AHP Ve Bulanık VIKOR Yöntemleri İle Otomotiv Sektöründe Risk Değerlendirmesi”, Mehmet Akif Ersoy Üniversitesi Sosyal Bilimler Enstitüsü Dergisi, 9(18), ss. 234-250.

Taghizadegan, Salman (2010), “Essentials Of Lean Six Sigma”,Elsevier, https://www.sciencedirect.com/book/9780123705020/essentials-of-lean-sixsigma\#book-info, (Erişim Tarihi: 15.04.2021)

The Institute of Internal Auditors (IIA) (2017), Lean Six Sigma Tools for Internal Audit, https://na.theiia.org/training/courses/CourseOutlines/Lean-Six-Sigma-Tools-forInternal-Audit.pdf, (Erişim Tarihi: 13.04.2021)

Türedi, Hasan-Karakaya, Gencay-İldem Mehmet (2015), “Kurumsal Yönetim ve İç Denetim İlişkisi” Sayıştay Dergisi, 96, ss. 55-74. 
Ulu Mesut-Şahin, Hasan (2020), "Hata Türü ve Etkileri Analizi Tekniği ile Bir Mühendislik Fakültesinde Risk Değerlendirmesi”, Electronic Letters on Science and Engineering, 16(2), ss.63-76. 
